\title{
Acute Myeloid Leukemia after Low-Dose Radioiodine Therapy for Papillary Thyroid Carcinoma
}

\author{
Arwa Alsaud Shehab Mohamed Mohamed A. Yassin Amr Ashour \\ Khaldun Obeidat Bahjat Azrieh
}

Hamad Medical Corporation, Doha, Qatar

Keywords

Leukemia $\cdot$ Radioiodine $\cdot$ Thyroid cancer

\begin{abstract}
Papillary thyroid carcinoma is the most common primary thyroid cancer. Most frequently treated with surgical resection, some cases require radioactive iodine (RAl) therapy. Studies have suggested that there is an increase in second primary malignancy after RAl therapy amongst thyroid cancer survivors including acute myeloid leukemia (AML) as an infrequent cancer related to RAI therapy; it has a higher relative risk ratio in patients on higher doses of radiation exposure. We would like to report a 30-year-old lady who was diagnosed with papillary thyroid carcinoma. She underwent total thyroidectomy and received a low-dose RAI ${ }^{131}$ I therapy at a dose of $150 \mathrm{mCi}$, after which she developed therapy-related AML. Here we would like to highlight the association of AML with low-dose RAI as an infrequent cause of a second primary tumor compared to high doses.

(C) 2020 The Author(s).

Published by S. Karger AG, Basel
\end{abstract}

\section{Introduction}

The thyroid gland located at the base of the neck is part of the endocrine system. It is responsible for the production, storage, and release of iodine-containing hormones from its thyroid follicles called tri-iodothyronine (T3) and thyroxine (T4) hormones which are necessary to regulate various vital body functions. It also secretes calcitonin hormone from its parafollicular cells, which is responsible for the regulation of blood calcium levels. The 
Alsaud et al.: Acute Myeloid Leukemia after Low-Dose Radioiodine Therapy for Papillary Thyroid Carcinoma

Table 1. Case reports of RAI therapy-induced AML in thyroid cancer [10-13]

\begin{tabular}{|c|c|c|c|c|c|c|c|c|}
\hline Case & $\begin{array}{l}\text { First Author } \\
\text { [Ref] }\end{array}$ & Age & Gender & Primary disease & $\begin{array}{l}\text { RAI } \\
\text { cumulative } \\
\text { dose }{ }^{131} \mathrm{I}\end{array}$ & $\begin{array}{l}\text { Time to } \\
\text { secondary } \\
\text { tumor }\end{array}$ & AML cytogenetics & Remission \\
\hline 1 & Schilling [10] & 34 & Female & Papillary thyroid carcinoma & $150 \mathrm{mCi}$ & 5 years & $\begin{array}{l}\text { Acute promyelocytic } \\
\text { leukemia } \\
\text { Not reported on } \\
\text { cytogenetics }\end{array}$ & Achieved \\
\hline 2 & Richards [11] & 28 & Male & $\begin{array}{l}\text { Mixed papillary and follicular } \\
\text { adenocarcinoma of thyroid }\end{array}$ & $621.6 \mathrm{mCi}$ & $\begin{array}{l}15 \\
\text { months }\end{array}$ & $\begin{array}{l}\text { APL, AML FAB M3 } \\
\text { T(15;17)(q22;21) }\end{array}$ & Achieved \\
\hline 3 & Bitton [12] & 28 & Female & $\begin{array}{l}\text { Metastatic follicular thyroid } \\
\text { cancer }\end{array}$ & $300 \mathrm{mCi}$ & $\begin{array}{l}14 \\
\text { months }\end{array}$ & $\begin{array}{l}\text { Acute myelogenous } \\
\text { leukemia }\end{array}$ & NA \\
\hline 4 & $\begin{array}{l}\text { Grudeva-Popova } \\
\text { [13] }\end{array}$ & 47 & Female & $\begin{array}{l}\text { Thyroid cancer (type not } \\
\text { specified) }\end{array}$ & NA & NA & t-APL t15;17(q22;q21) & Achieved \\
\hline
\end{tabular}

NA, not available.

thyroid gland is covered by a fibrous capsule that extends a thin collagenous septum to divide the follicles into lobules [1].

Thyroid cancer can be subclassified into differentiated or undifferentiated thyroid cancer depending on the epithelial cell the tumor cells are derived from. Papillary thyroid cancer is the most common type of differentiated thyroid cancer, which comprises the vast majority (>85\%) of all thyroid cancers. This is followed by follicular thyroid cancer and anaplastic (undifferentiated) thyroid cancer [2].

The basic goals of initial therapy for patients with papillary thyroid cancer would be to improve survival and reduce disease recurrence. Initial therapy following risk stratification of the disease burden is by surgical resection of the primary tumor and adjacent metastatic lymph nodes as it is an important factor in determining disease outcome, while residual metastatic lymph nodes represent the most common site of disease persistence/recurrence. Other therapies such as radioactive iodine (RAI) treatment, TSH suppression or other adjuvant therapies might be necessary in certain cases [3].

Leukemia is a type of blood cancer that affects the bone marrow and there are two forms: acute and chronic leukemia. Acute myeloid leukemia (AML) is characterized by a rapid increase in the number of immature white blood cells. In most cases with RAI therapy-induced leukemia reported in the literature it developed after higher cumulative doses of RAI therapy [4] (Table 1).

Here we present a rare case of acute leukemia secondary to radioiodine-induced therapy after a low dose of ${ }^{131}$ I of $150 \mathrm{mCi}$.

\section{Case Presentation}

Our patient was a 30-year-old female diagnosed with hyperthyroidism in 2013. Later on her US thyroid showed thyroid enlargement with focal lesions in the right lobe containing tiny areas of punctate calcification giving rise to a suspicion of papillary thyroid carcinoma. ${ }^{99} \mathrm{Tc}$ thyroid scan revealed multinodular goiter with two cold nodules in the right lobe. In June 2015 the patient underwent total thyroidectomy with level VI lymph node dissection. Histopathology revealed multifocal well-differentiated papillary thyroid cancer with deposits in 
Alsaud et al.: Acute Myeloid Leukemia after Low-Dose Radioiodine Therapy for Papillary Thyroid Carcinoma

the local lymph nodes. In July 2015, she received RAI ${ }^{131}$ I therapy at a dose of $150 \mathrm{mCi}$ orally. A thyroid scan done at this time revealed significant residual thyroid tissue in the neck. A follow-up ${ }^{131}$ I scan at a 3-mCi dose revealed complete ablation. She was doing well on her follow-up post-treatment.

Sixteen months later the patient was admitted with acute menorrhagia and symptomatic anemia. Her peripheral smear revealed severe anemia, thrombocytopenia, and leukocytosis with many circulating blasts suggestive of acute leukemia. Flow cytometry of bone marrow aspirate was consistent with AML with $29 \%$ blasts and $44 \%$ monocytes. Chromosome analysis revealed 46,XX,inv(16)(p13.1q22)CBFB-MYH11 cytogenetic abnormality.

After her diagnosis she received two cycles of induction with a $(3+7)$ protocol, to which she responded well and achieved complete remission.

\section{Discussion}

Thyroid cancer is classified into differentiated or undifferentiated depending on the epithelial cell the tumor cells are derived from. Differentiated thyroid cancers account for $>95 \%$ of thyroid cancer with papillary thyroid cancer as the most common type of differentiated thyroid cancer (85\%) followed by follicular thyroid cancer [2].

Papillary thyroid carcinoma is the most common primary thyroid cancer with an incidence of 15.8 per 100,000 individuals every year. It has an excellent prognosis with a survival rate of more than $90 \%$ [5].

The primary treatment for papillary thyroid cancer is surgery. For patients undergoing RAI remnant ablation, or RAI treatment of presumed (adjuvant therapy) or known (therapy) residual or metastatic disease, removal of all normal thyroid tissue is an important element of initial surgery [3].

RAI therapy is a type of nuclear medicine treatment, the principle of which involves systemic ingestion of ${ }^{131}$ I with, thereafter, the selective absorption of the drug carrying the radioactive element in it, resulting in a zone of localized high-radiation dosage in the selective absorption tissues to destroy any remnant of normal thyroid tissue after total thyroidectomy [6]. RAI therapy is reported to increase the risk of a second primary malignancy. In a systematic review it was observed, although rarely, that patients had a higher risk of subsequent leukemia after thyroid cancer treated with iodine therapy [7].

Therapy-related acute myeloid neoplasms (t-AML) is a type of AML that is caused by previous treatment with chemotherapy or radiation therapy such as alkylating agents, ionizing radiation therapy, topoisomerase II inhibitors, and others [8].

In a 2016 review of 37 patient with t-AML the most common subtype noted was trans $t(15 ; 17)$, less commonly inv(16) type reported after RAI therapy [4, 9].

In this report we would like to highlight (1) the association of AML with low-dose RAI as an infrequent cause of a second primary tumor compared to high doses, (2) how chromosome abnormality associated with 46,XX,inv(16)(p13.1q22)CBFB-MYH11 was a an uncommon mutation in our case compared to RAI therapy-induced leukemia that has shown a favorable response, and (3) how it compares to other RAI therapy-related AML reported in the literature.

\section{Conclusion}

Very high doses of RAI (exceeding $600 \mathrm{mCi}$ ) have been known to increase the risk of acute leukemia. However, leukemia following a lower dose of RAI can also occur. 
Alsaud et al.: Acute Myeloid Leukemia after Low-Dose Radioiodine Therapy for Papillary Thyroid Carcinoma

\section{Acknowledgment}

We would like to thank the Qatar National Library for supporting this publication and the Internal Medicine Residency Program for supporting the residents' research.

Statement of Ethics

Consent was obtained from the patient.

Disclosure Statement

The authors have nothing to disclose.

\section{Funding Sources}

This article was funded by the Qatar National Library.

\section{Author Contributions}

Arwa Alsaud, Mohamed A. Yassin: manuscript writing and editing. Amr Ashour, Khaldun Obeidat, Bahjat Azrieh, and Shehab Mohamed: clinical management.

\section{References}

1 Thyroid Histology / Pathway Medicine [Internet]. [cited 2019 Dec 8]. Available from: http://www.pathwaymedicine.org/Thyroid-Histology

2 Differentiated thyroid cancer: overview of management - UpToDate [Internet]. [cited 2019 Dec 8]. Available from:https://www.uptodate.com/contents/differentiated-thyroid-cancer-overview-of-management?search $=$ thyroid cancer\&source $=$ search_result\&selectedTitle $=1 \sim 150 \&$ usage_type $=$ default\&display_rank $=1$

3 Haugen BR, Alexander EK, Bible KC, Doherty GM, Mandel SJ, Nikiforov YE, et al. 2015 American Thyroid Association Management Guidelines for Adult Patients with Thyroid Nodules and Differentiated Thyroid Cancer: The American Thyroid Association Guidelines Task Force on Thyroid Nodules and Differentiated Thyroid Cancer. Thyroid. 2016 Jan;26(1):1-133.

4 Oluwasanjo A, Pathak R, Ukaigwe A, Alese 0. Therapy-related acute myeloid leukemia following radioactive iodine treatment for thyroid cancer. Cancer Causes Control. 2016 Jan;27(1):143-6.

5 Ito Y, Miyauchi A, Kihara M, Fukushima M, Higashiyama T, Miya A. Overall survival of papillary thyroid carcinoma patients: a single-institution long-term follow-up of 5897 patients. World J Surg. 2018 Mar;42(3):615-22.

6 Buscombe J. Therapeutic nuclear medicine in the UK. In: A history of radionuclide studies in the UK: 50 th anniversary of the British Nuclear Medicine Society. Cham: Springer International Publishing; 2016. p. 121-8.

7 Yu CY, Saeed O, Goldberg AS, Farooq S, Fazelzad R, Goldstein DP, et al. A systematic review and meta-analysis of subsequent malignant neoplasm risk after radioactive iodine treatment of thyroid cancer. Thyroid. 2018 Nov.

8 Döhner H, Estey EH, Amadori S, Appelbaum FR, Büchner T, Burnett AK, et al. Diagnosis and management of acute myeloid leukemia in adults: recommendations from an international expert panel, on behalf of the European LeukemiaNet. Blood. 2010 Jan;115(3):453-74.

9 Jeong JH, Ahn JY, Park SH, Park MJ, Kim KH, Hong JS. A case of therapy-related acute myeloid leukemia with inv(16)(p13.1q22) after single low-dose iodine-131 treatment for thyroid cancer. Korean J Hematol. 2012;47(3):225-8.

10 Schilling VR, Abellan PF, Dominguez E, Gonzalez CR, Barbera EM, Cendra RC. Acute leukemias after treatment with radioiodine for thyroid cancer. Haematologica. 1998 Jan 1;83(8):767-8. 
11 Richards EM, Marcus RE. Acute promyelocytic leukaemia following radioiodine therapy. Clin Lab Haematol. 1993;15(1):55-8.

12 Bitton R, Sachmechi I, Benegalrao Y, Schneider BS. Leukemia after a small dose of radioiodine for metastatic thyroid cancer. J Clin Endocrinol Metab. 1993 Nov;77(5):1423-6.

13 Grudeva-Popova J, Yaneva M, Zisov K, Ananoshtev N. Therapy-related acute promyelocytic leukemia after treatment with radioiodine for thyroid cancer: case report with literature review. J BUON. 2007 Jan;12(1):12932. 